\title{
Editorial
}

\section{Hacia una plena inclusión en Odontología: estomatología para pacientes especiales, nuevos retos para todas las sonrisas}

\author{
Towards full inclusion in \\ Dentistry: stomatology for \\ special patients, new challenges \\ for all smiles
}

Edith Falconí Salazar 1,a

${ }^{1}$ Asociación Sociedad Peruana de Odonto Estomatología de Pacientes Especiales (ASPODES), Lima, Perú.

a Especialista en Estomatología para Pacientes Especiales. Presidenta de ASPODES

\section{Correspondencia:}

Edith Falconí Salazar: litafalconi@gmail.com

Alameda del Corregidor 1271 La Molina, Lima Perú.

ORCID: 0000-0003-1271-3887

Recibido: 24/11/20

Aceptado: $18 / 12 / 20$

Publicado: 15/02/21
"El punto de partida de toda reflexión sobre la discapacidad radica en los principios fundamentales de la antropología cristiana: la persona con discapacidad, aunque se encuentre debilitada en sus capacidades físicas, sensoriales o intelectuales, es un ser humano, con los derechos sagrados e inalienables propios de todo ser humano, independientemente de las condiciones en las que se desarrolla su vida y de las capacidades que puede expresar, posee una dignidad única y un valor singular desde el inicio de su existencia hasta el momento de la muerte natural" (San Juan Pablo II, Vaticano, 5 de enero de 2004).

Las personas con discapacidad, son de los grupos más marginados y excluidos de la sociedad, sus derechos son vulnerados de manera generalizada. Debido a su discapacidad o enfermedades sistémicas requieren atención especial de salud, entornos accesibles, ayudas técnicas y eliminar barreras.
La Agenda 2030 para el Desarrollo Sostenible, insta a no dejar a nadie atrás y llamó a trabajar unidos para concretar ese compromiso de reducir la desigualdad y promover la inclusión social, económica y política de todos, incluidas las personas con discapacidad ${ }^{1}$.

En Odontología, el término pacientes especiales y/o con discapacidad incluyen al paciente niño o adulto médicamente comprometido, al que presenta alguna discapacidad, que lo alejan de la normalidad, ya sean de orden físico, mental, sensorial o de comportamiento y que, para su atención odontológica, exige maniobras, conceptos y una capacidad de atender las necesidades que estos generan, escapando de los programas y rutinas habituales que se llevan a cabo para el mantenimiento de la salud bucodental de la población general ${ }^{2}$.

En 2004 la Comisión de Acreditación Dental y la Asociación Americana de Discapacidad Intelectual, adoptaron estándares para los programas de educación para 
asegurar la preparación de los profesionales que brindan servicios de salud bucal a personas con necesidades especiales. Esto amplía la definición de la administración de servicios y recursos de salud de áreas médicamente desatendidas siendo un enfoque para mejorar la atención en los servicios dentales ${ }^{3}$. Las escuelas de Odontología en EEUU entonces, preparan a sus graduados para el diagnóstico y tratamiento de los pacientes con necesidades de salud especiales ${ }^{4}$.

A nivel mundial, $15 \%$ de personas tiene una discapacidad. En el Perú, 10\% de la población presenta alguna discapacidad y se define como: "aquella que tiene una o más deficiencias físicas, sensoriales, mentales o intelectuales de carácter permanente que, al interactuar con diversas barreras actitudinales y del entorno, no ejerza o pueda verse impedida en el ejercicio de sus derechos y su inclusión plena y efectiva en la sociedad, en igualdad de condiciones que las demás" 5 . Por lo tanto, mientras más barreras, más discapacidad.

Existen muchas investigaciones que afirman que las personas con discapacidad presentan ciertas condiciones que las hacen ser una población de riesgo para enfermedades bucales; además, tienen dificultad para realizarse la higiene bucal, dependencia de atención, ingesta de medicamentos, falta de conciencia de la necesidad de cuidado bucal por parte de padres o cuidadores, ausencia o déficit de recursos humanos capacitados, entre otros.

Muchos dentistas no brindan servicios a las personas con discapacidad, sus razones con frecuencia son: los altos costos y tiempo que requieren su atención, presentan comportamiento desafiante, ocasionan disturbios en la sala de espera, la necesidad de instalaciones especiales y la falta de formación y experiencia ${ }^{6}$.

A estas barreras se suman:

- La prioridad que tienen los padres de familia hacia otras necesidades como el tener que llevar a sus hijos a varios tratamientos y terapias de rehabilitación física, sensorial, de lenguaje, etc. Esto motiva, muchas veces, que los padres dejan de lado la atención odontológica.

- Los determinantes sociales de la salud oral crean desigualdades significativas para las personas con discapacidad.

- Problemas con la organización local de atención de la salud; falta de financiamiento del estado para la atención de la salud bucal de esta población vulnerable.

- Accesibilidad limitada debido a barreras arquitectónicas, de transporte, económicas y otras.

- La formulación de políticas no siempre tiene en cuenta las necesidades de las personas con discapacidad, o bien, no se cumplen las normas existentes.

- Prestación insuficiente de servicios. Las personas con discapacidad son particularmente vulnerables a las deficiencias que presentan los servicios ${ }^{7}$.
- Falta de especialistas, que son la fuerza de trabajo odontológico para nuestra población vulnerable y quienes tienen las competencias para hacerlo.

La formación del recurso humano para la atención odontológica de pacientes especiales, con discapacidad, es un reto; es un tema muy complejo, una tarea muy difícil de resolver aunque no imposible, debido a las características propias de cada discapacidad, de cada condición biológica, sistémica y comportamental de nuestros pacientes.

Los planes de estudio de las carreras de Odontología de las universidades estatales y privadas carecen en general de asignaturas específicas que abarquen el abordaje del paciente con discapacidad y en varias se aborda como una unidad más, dentro del programa de contenidos de una asignatura que podríamos llamarla afín. En la Universidad de Cuyo, Mendoza, Argentina, se inició lanzando un curso optativo, que despertó tal interés que en la reformulación del plan de estudios del 95 se incorporó como obligación curricular el Seminario de Atención Odontológica del Paciente Discapacitado, teoría con práctica sobre pacientes ${ }^{8}$.

La situación actual de la atención odontológica en el Perú para las personas con discapacidad o con compromiso sistémico es crítica e incierta, muy difícil, por múltiples factores que van desde la falta de investigación, centros médicos, de rehabilitación que no cuentan con consultorios odontológicos accesibles, los planes de estudio de las facultades o escuelas de Odontología carecen de asignaturas específicas en el pregrado, para el abordaje de personas con discapacidad, y a nivel de posgrado la mayoría de universidades no tienen la especialidad. Actualmente solo la Universidad Peruana Cayetano Heredia tiene la especialidad de Estomatología para Pacientes Especiales; la Universidad Inca Garcilaso de la Vega contaba con la especialidad pero ha tenido inconvenientes con su acreditación. Por lo tanto, son pocos los odontólogos especialistas para resolver la complejidad que presentan las personas con discapacidad.

La historia de la docencia en pacientes especiales se inicia en 1951: en el Congreso anual de la Sociedad Americana de Odontopediatría, en Washington. Los odontopediatras ven la dificultad de incluir a los niños con discapacidad en este ámbito, por lo cual se funda en 1952 la "Academia de Odontología para la Rehabilitación Oral de las Personas con Discapacidad", actualmente se le conoce como Academy of Dentistry for Persons with Disabilities (ADPD).

A partir de ese momento se desarrollan programas de posgrado y pregrado en diferentes universidades estadounidenses, incluso la formación de higienistas y auxiliares en estas materias. En los años 1960 se comienza a formar un organismo internacional que celebra su primer congreso en 1971 en Atlantic City, la IADH, International Association for Disability and Oral Health, institución mundial conformada por las principales sociedades nacionales; dentro de sus logros se encuentra haber trabajado el currículo de grado en odontología 
para pacientes con discapacidad o riesgo médico, el cual incluye metodologías educativas complementarias y de evaluación que constituirán la base de la formación continua de los odontólogos ${ }^{9}$.

En Perú, un grupo de odontólogos competentes que trabajamos desde muchos años atrás en diferentes centros de rehabilitación, hospitales e instituciones educativas, dedicados a la atención de pacientes especiales, decidimos formalizarnos como sociedad científica, es así que fundamos la Asociación Sociedad Peruana de Odonto Estomatología de Pacientes Especiales (ASPODES), primera asociación odontológica peruana dedicada a mejorar la salud bucal de personas con discapacidad y enfermedades sistémicas; ASPODES es miembro de la IADH, reconocida por el Colegio Odontológico del Perú y la Academia Interamericana de Odontología para Pacientes Especiales (AIOPE). Desde el 2007 ASPODES participa activamente en la actualización y capacitación de los odontólogos para la atención de pacientes con discapacidad; organizando congresos, jornadas científicas nacionales e internacionales, cursos internacionales y encuentros científicos; brindando programas de atención para mejorar e incentivar a los odontólogos a trabajar con calidez y calidad humana a los pacientes especiales; contribuyendo a la motivación en la formación de especialistas, promoviendo actividades para mejorar la salud bucal de personas con discapacidad, es así que desde su fundación se ha venido realizando campañas en conjunto con universidades como la Universidad Nacional Mayor de San Marcos, la Universidad Peruana Cayetano Heredia, la Universidad de San Martín de Porres y la Universidad Inca Garcilaso de la Vega, así como realizando programas de atención preventiva en diferentes instituciones de personas con discapacidad llegando a tener más de 2000 personas con discapacidad beneficiarias.

El acceso a los cuidados orales es un derecho humano que el profesional odontólogo debe promover, nuestra obligación ética es ofrecer igual estándar de cuidados a todas las personas, tengan o no discapacidad. Las organizaciones odontológicas tenemos un rol importante en el desarrollo de políticas, en promover y motivar que se reconozca la especialidad, la situación en que se encuentra los cuidados de salud oral de las personas con discapacidad, necesitamos ver el contexto de las inequidades y disparidades, tenemos la obligación de realizar programas y actividades para personas con discapacidad ${ }^{10}$.

Creemos que podemos mejorar si unimos esfuerzos, para lo cual debemos tomar medidas urgentes como:

- Promover que todas las universidades tengan asignaturas específicas en la currícula del pregrado para motivar a los alumnos acerca de la atención a personas con alguna discapacidad, de igual modo, todas las universidades del país, sean facultad o escuela de odontología, deben tener la especialidad de Estomatología para Pacientes Especiales en el posgrado, de ese modo el recurso humano tendrá las competencias necesarias para la atención odontológica de las personas con alguna discapacidad, riesgo médico u odontología hospitalaria.

- Los hospitales deben contratar a los especialistas en Estomatología para Pacientes Especiales pues son quienes tienen las competencias en las unidades de odontología hospitalaria, donde deberían realizar todas las especialidades odontológicas de forma integrada en los pacientes con discapacidad, en pacientes con enfermedades crónicas, pacientes hospitalizados, pacientes en riesgo, posibilitando la interconsulta con otros especialistas en temas multidisciplinarios o complejos; se debe promover el trabajo en equipo con la presencia del odontólogo especialista dentro del equipo.

- Que las autoridades gubernamentales promulguen leyes para mejorar la atención, la infraestructura de los servicios odontológicos, para una mejor accesibilidad de las personas con discapacidad, que disminuya las barreras, así también el Ministerio de Salud en unión con las instituciones especializadas debe dar los lineamientos y guías para la atención multidisciplinaria desde el nacimiento del bebe en riesgo, así se crean consensos entre los diferentes especialistas del equipo multidisciplinario.

- Debemos involucrar a la familia, sensibilizar a la sociedad y crear conciencia sanitaria preventiva en los temas de cuidado de salud bucal como parte de la salud y desarrollo integral.

Nosotros en ASPODES consideramos que debemos llegar al bicentenario del Perú derribando barreras de exclusión en odontología, sumando esfuerzos, uniéndonos para compartir y no para competir, debemos unirnos por las personas más vulnerables y desatendidas, las personas con alguna discapacidad o riesgo médico, solo así lograremos una odontología inclusiva y ayudaremos a mejorar todas las sonrisas.

\section{Referencias bibliográficas}

1. Ban Ki-moon. Organización de las Naciones Unidas, Personas con discapacidad. Departamento económicos y sociales [Consultado el 4 de Diciembre 2020]. Accesible en: https://news.un.org/es/story/2021/01/1486492

2. Silvestre FJ. Plaza A, Odontología en pacientes especiales. Universitat de Valencia; 2007. p. 15-16.

3. Waldman HB, Perlman SP. Mandating education of dental graduates to provide care to individuals with intellectual and developmental disabilities. Ment Retard 2006;44(3):184-8.

4. Krause M, Vainio L, Zwetchkenbaum S, Inglehart MR. Dental Education About Patients with Special Needs: A Survey of U.S. and Canadian Dental Schools. J Dent Educ. 2010;74(11):1179-89.

5. Congreso de la República del Perú, Ley de la persona con discapacidad. Cap. 1, Artículo 2. Definición de persona con discapacidad. 2012

6. Nunn J. Disability and oral care. International Journal of Dental Sciences and Research. 2018;6(6):148-154. DOI: $10.12691 /$ ijdsr-6-6-2 
7. Organización Mundial de la Salud, Informe Mundial de la Discapacidad y Grupo del Banco Mundial OMS; 2011. Disponible en: www.who.int/disabilities/world_ report/2011/report.pdf.

8. Nasso P, Salazar E. La salud oral de grupos poblacionales vulnerables: experiencias de educación para la salud bucal en niños con discapacidad en Perú y Argentina. Revista de la Facultad de Odontología. 2010;4(2):7-11.
9. Machuca G, Bullón Fernández P. Tratamiento Odontológico en Pacientes especiales. 2da ed. Madrid: Lab. Norton; 2004.

10. Benzian H, Simposio Oral Health and disabilities, Policies to reduce inequalities, FDI World dental federation, Sweden; 2006. 